\title{
Comparison of the thermal effects of Coblation and Radiofrequency waves in a porcine turbinate model
}

\author{
Klaus Vogt' ${ }^{1}$ Inese Daine-Loza', Maris Sperga² \\ ${ }^{1}$ University of Latvia, Faculty of Medicine, Center of Experimental Surgery, Riga, Latvia \\ ${ }^{2}$ Pathology Center, Riga East Clinical University Hospital, Riga, Latvia
}

\begin{abstract}
BACKGROUND. Radiofrequency reduction and Coblation are widely used procedures for the treatment of functionally enlarged turbinates with an appropriate outcome. Bleeding and crusting are postoperative complications for Coblation. Thermographic measurements and histological analyses were used to elucidate the causes.

MATERIAL AND METHODS. In a porcine turbinate model, double-needle electrodes of different lengths were tested using a $4 \mathrm{MHz}$ radiofrequency current with either automatic energy limitation or a predetermined energy amount of $200 \mathrm{~J}$. Coblation, according to the manufacturer's instructions, was carried out with a Reflex Ultra 45 wand. The generated temperature was measured with thermo-probes at the tip of the electrodes. The mucosa was subsequently investigated histologically.

RESULTS. Without preoperative saline injection, all procedures generate temperatures $<100^{\circ} \mathrm{C}$. After saline injection, excessive temperatures are reached by Coblation after the release of plasma in a closed system. The follow-up is a severe deterioration of the microscopic structures of the mucosa. The low-temperature advantages of Coblation are only effective if the mandatory saline solution rinses the surface. The Radiofrequency applications deliver more predictable results.
\end{abstract}

CONCLUSION. For the treatment of the functional enlargement of the turbinates, Radiofrequency current with proofed settings should be chosen.

KEYWORDS: turbinate reduction, coblation, radiofrequency ablation, temperature measurements, tissue damage.

\section{INTRODUCTION}

The surgical treatment of nasal turbinates is certainly one of the most frequent procedures in rhinology due to the importance of the turbinates for the resistance of the entire airway. A large number of publications exist discussing various energy-based treatment modalities of turbinate hyperplasia. In 2000, Hol and Huizing ${ }^{1}$ had already listed 141 publications since the year 1845, which mark the beginning of studies on energy-based turbinate treatment. In a recent paper, Passali et al. ${ }^{2}$ drew on their own former publications and referred to additional reports on the application of Radiofrequency ablation and Coblation. Through postoperative investigations, the authors have found these methods to have almost the same outcomes. They reported a remarkable reduction of nasal airway resistance and an increase in the nasal cross-sectional area for one year postoperatively, as well as a low recurrence rate with increasing resistance over a period of three years. Shah ${ }^{6}$ reported favourable outcomes of Coblation turbinate reduction compared to bipolar electrosurgery intramural reduction. Vogt and Enache $^{3}$, in a retrospective study, described 150 cases of Radiofrequency (RF) turbinate reductions evaluated by pre- and postoperative 4-phase rhinomanometry. Cukurova et al. ${ }^{4}$ reported the same good experience regarding the application of Radiofrequency in 197 cases after control by acoustic rhinometry and a VAS-scale. Bran ${ }^{7}$ et al. reported excellent results with $4 \mathrm{MHz}$ bipolar Radiofrequency ablation of the inferior turbinates in a prospective, single-blinded, placebo-controlled crossover trial. In summary, RFturbinate reduction and Coblation seem to be frequently used methods for the treatment of turbinate hyperplasia.

Coblation claims to be a low-temperature technology ("cold ablation"), where plasma created at the tip of the instrument breaks the molecular structures and disintegrates tissue ${ }^{8}$. According to the manufacturer, 
the temperature in the tissue will be around $60^{\circ} \mathrm{C}$. With $4 \mathrm{MHz}$ Radiofrequency claiming to be a minimally-invasive, gentle method of creating tissue lesions, it is well suited for the delicate resection of structures at minimally lateral thermal damage when cutting through tissue $e^{9,10}$.

The aim of any energy-based method for reduction of the turbinates should be as follows:

- Decreasing the blood supply to reduce excessive swelling;

- Preserving the mucociliary epithelium;

- Minimizing postoperative bleeding and the duration of postoperative care;

- Achieving long-term relief of symptoms.

From a technical point of view, the procedure has to produce a precisely circumscribed submucosal lesion. Excessive heat will lead to unwanted tissue damage, potentially leading to turbinate bone necrosis or mucosal necrosis. Such effects would have a negative impact on wound healing, postoperative pain, preservation of the turbinate function and recovery in general. Additionally, due to the immense impact on the quality of life, such a routine method should be available at reasonable costs per procedure.

The aim of this experimental in-vitro study was to measure and map the temperature at the tip of the electrodes of a bipolar $4 \mathrm{MHz}$ RF system and of a Coblation wand in a porcine turbinate model. A histological evaluation of tissue damage was performed to verify and validate the thermal measurements and with the intention of gaining further insights on the tissue effects of the two technologies.

\section{MATERIAL AND METHODS}

\section{Turbinate specimens and histological analysis}

We used the lower turbinates of freshly slaughtered pigs, which are comparable to human turbinates and only differ in length and cross section. The mucosa has a similar thickness. Porcine lower turbinates are fully pneumatized, and the bony structures are thin, which is helpful as they can easily be removed for experimental purposes (Figure 1).

The specimens were fixed in a $4 \%$ formalin solution and processed in a specialized laboratory (Laboratory Dr. Hartig, Buchholz, Nordheide/Germany). They were stained with HE (hematoxylin and eosin). For the numeric evaluation of the histological specimens, an OLYMPUS BX 43 F microscope with a UC30 camera was used, with program Cell D 3.4.

\section{Energy-based devices and electrodes}

For the Coblation experiments, a Coblator II (Arthrocare/Smith\&Nephew) with a Reflex Ultra 45 wand was used (Figure 2, Figure 3). The coblator operates at a fre-
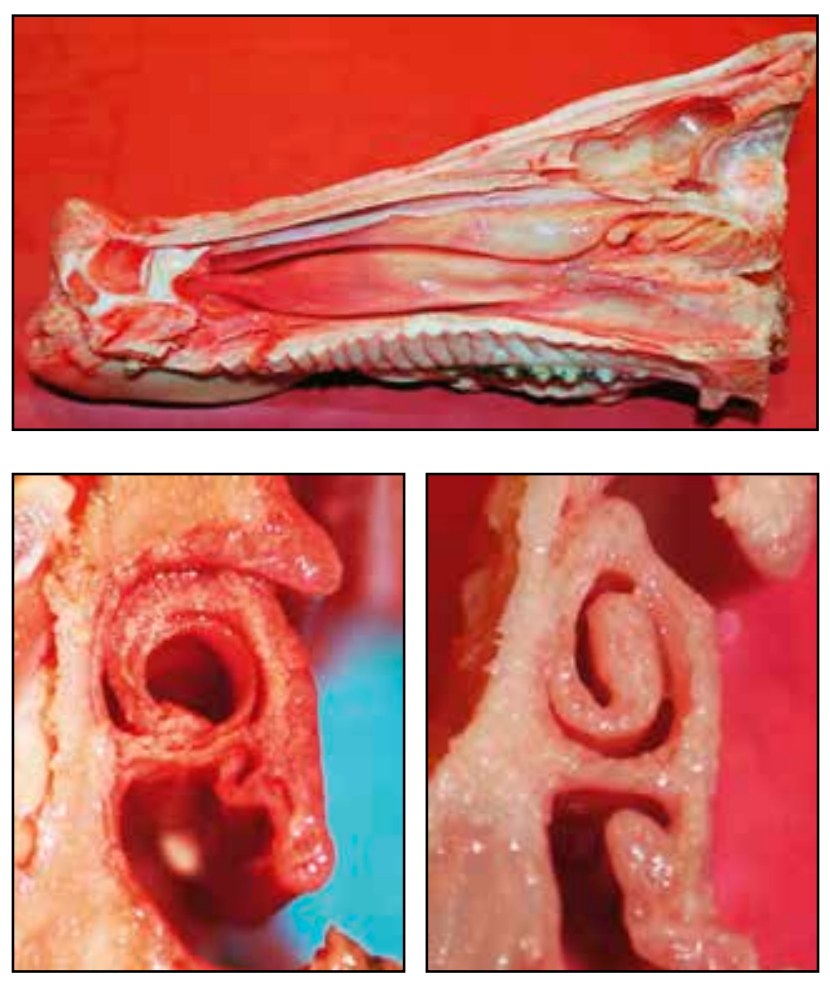

Figure 1 Turbinates of the pig (sagittal and 2 cross sections).

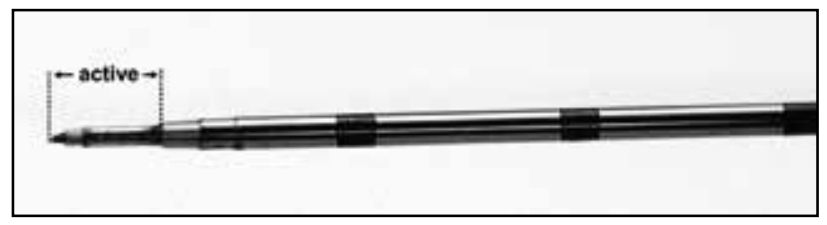

Figure 2 Reflex Ultra 45 wand.

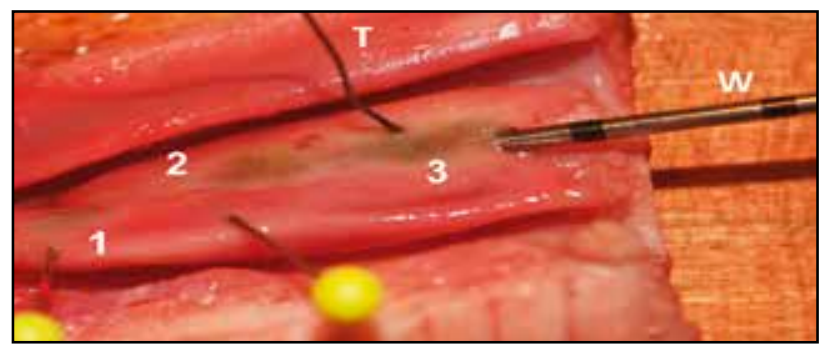

Figure 3 Right lower turbinate of a pig after 3rd lesion by Coblation. 1, 2, 3 - subsequent lesions, $\mathrm{T}$ - thermo-probe, $\mathrm{W}$ - wand. The lesions are marked by needles for the histological evaluation.

quency of $100.1 \mathrm{kHz}$. Saline fluid irrigation, which is normally applied for Coblation dissections, cannot be used during the "channelling" procedure under the turbinate mucosa and it is replaced by saline gel as per the manufacturer's instructions. The wand works via a bipolar concentric electrode and it was used in three submucosal locations lying $1 \mathrm{~cm}$ apart. The diameter of the electrode is $1.94 \mathrm{~mm}$. The wand was activated at each location for 10 seconds in the ablation mode, at intensity level 6 , as per the recom- 


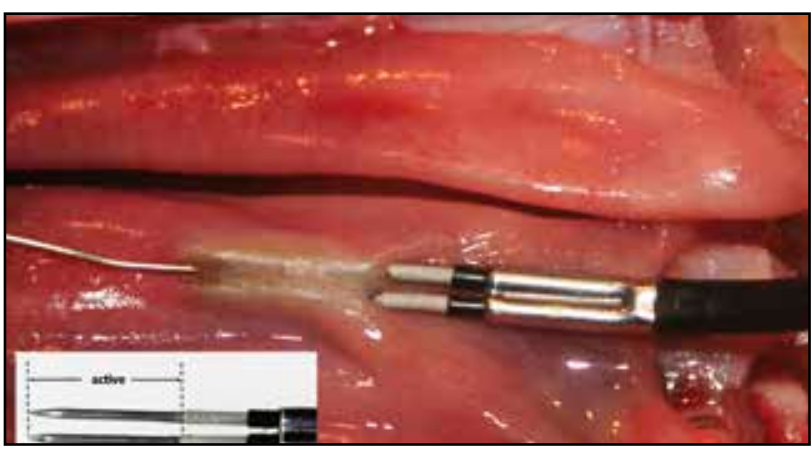

Figure 4 Bipolar electrode with $10 \mathrm{~mm}$ working length in the left lower turbinate, with a thermo-probe between the tips and after delivery of $200 \mathrm{~J}$.

mendations by Shah et al. ${ }^{6}$ and following the instructions of the manufacturer. To simulate the real surgical procedure, which would mostly be performed under local anaesthesia, experiments were carried out with and without injection of $0.9 \%$ saline solution as an isotonic medium.

For the application of Radiofrequency energy with a frequency of $4 \mathrm{MHz}$, the CURIS microsurgical RF generator (Sutter GmbH, Freiburg/Germany) was used. In our experimental set-up, we used two slightly different electrode types: a bipolar parallel needle electrode with $10 \mathrm{~mm}$ active length and a protective insulation proximal to the active part to protect the mucosa after insertion. The diameter of the needle is $0.8 \mathrm{~mm}$, and the distance between the tips is $2.0 \mathrm{~mm}$ (Figure 4). This "Binner" needle is commonly offered with the CURIS Generator.

The second electrode design differed only in the length of the active portion of the electrode. Instead of $10 \mathrm{~mm}$ active length, it had an active length of $25 \mathrm{~mm}$ (Figure 5). Since we found no significant difference in the temperature profile between the two versions, only the results for the $10 \mathrm{~mm}$ needle are presented.

The CURIS generator was operated in the RaVoR mode at a setting of 10 watts. This mode was specifically designed for interstitial bipolar ablation. It controls energy delivery by measuring tissue impedance and stops energy delivery automatically. Again, like with the Coblation experiment, the procedures were

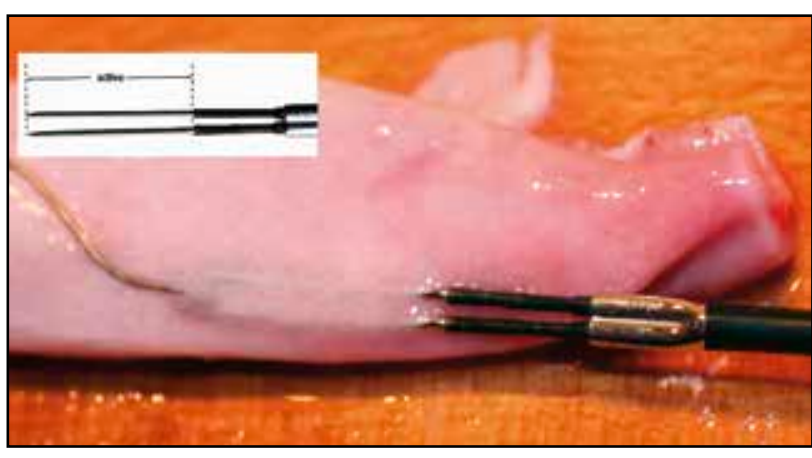

Figure 5 Bipolar electrode, $25 \mathrm{~mm}$ working length, before activation. A thermo-probe is inserted between the tips of the needles.

carried out with and without injection of $0.9 \%$ saline solution as an isotonic medium.

\section{Temperature measurements}

For temperature measurements, a Voltcraft IR 1200-50D USB device was used with a cable thermoprobe and the datalogger software Voltsoft Pro.

\section{Procedure of the experiments}

In a series of two experiments, the electrodes were submucosally inserted either without an injection of saline or after injection of $2-3 \mathrm{ml}$ of a $0.9 \%$ saline solution. After electrode insertion, the thermo-probe was placed in close proximity to the active electrode inside the turbinate tissue. Tissue temperature before activation was measured as a baseline. Room temperature was recorded throughout the procedure for reference. Tissue temperature was recorded at the beginning of the activation, during and following activation at intervals of one second until, after deactivation, the approximate level of the start temperature was reached again.

\section{RESULTS}

A. Results of the thermal measurements

In Table 1, the results of the measurements during and after the activation of the electrodes are summa-

Table 1

Comparison of the mean temperatures through all measurements.

\begin{tabular}{|c|c|c|c|c|}
\hline & Coblation & & RaVoR & \\
\hline & without saline & with saline & without saline & with saline \\
\hline Mean & 59.5 & 273.5 & 56.4 & 50.5 \\
\hline Median & 52 & 87.05 & 48.75 & 41.45 \\
\hline Standard deviation & 45.2 & 285.2 & 21.8 & 21.9 \\
\hline N & 57 & 114 & 240 & 120 \\
\hline
\end{tabular}




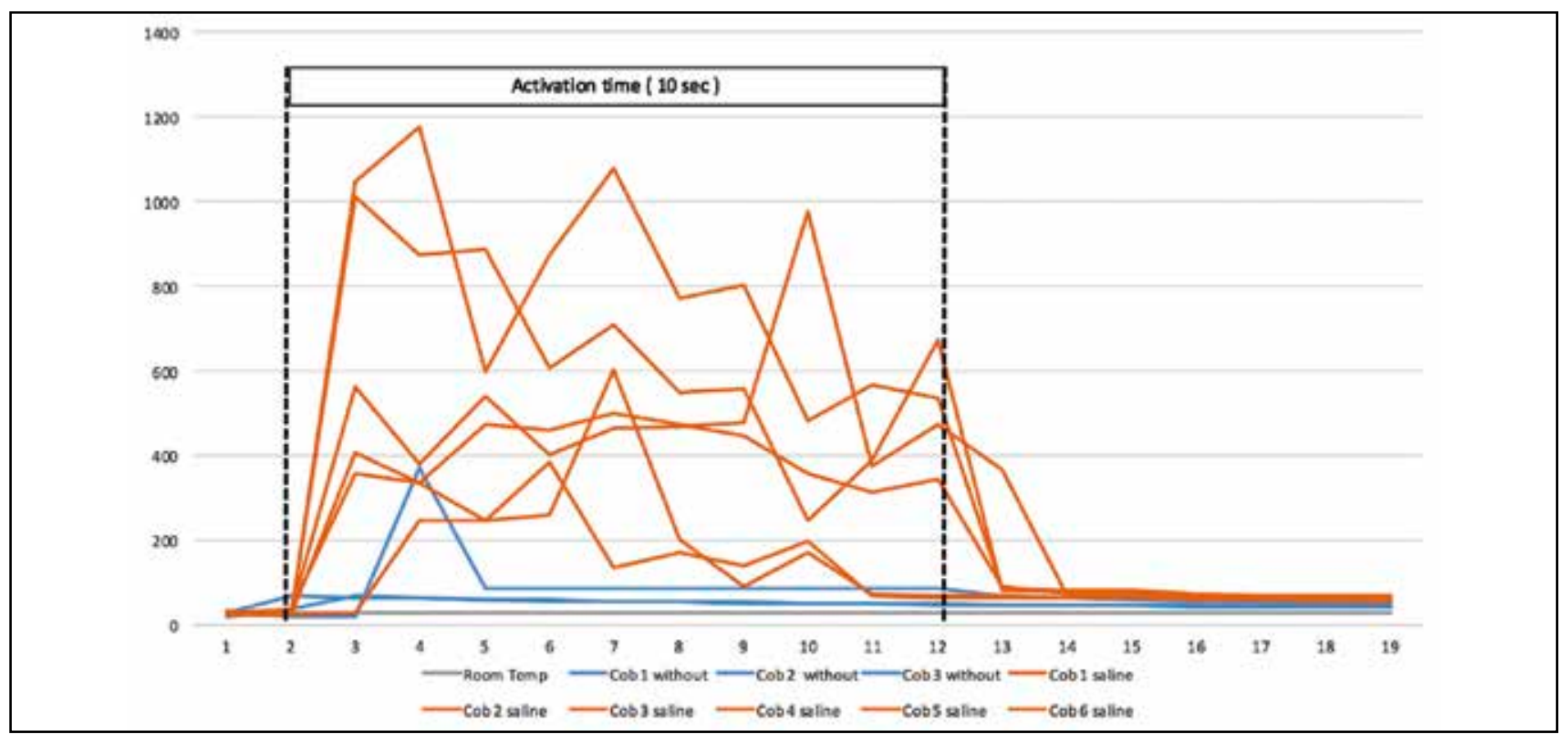

Figure 6 Timeline of temperature $\left({ }^{\circ} \mathrm{C}\right)$ during and after Coblation activation with and without saline injection.

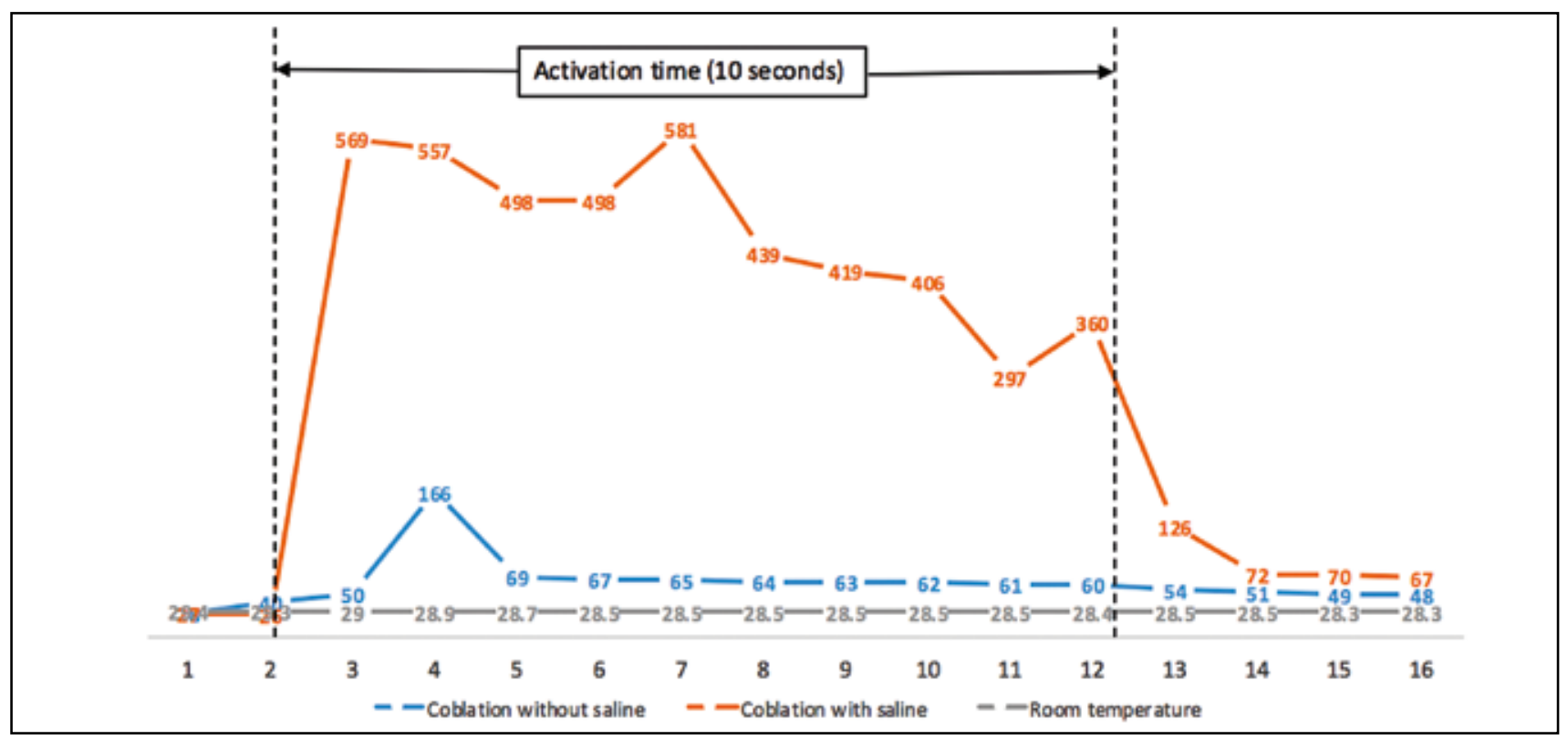

Figure 7 Mean temperature during Coblation $\left({ }^{\circ} \mathrm{C}\right)$ with and without saline injection.

rized. The timeline of the temperature during the coblation experiments and the mean timeline are shown in Figures 6 and 7.

In all Coblation experiments after the saline injection, temperatures were extremely high after activation. They averaged between $300^{\circ} \mathrm{C}$ and $600^{\circ} \mathrm{C}$ with peak temperatures briefly exceeding $1000^{\circ} \mathrm{C}$. The reason for this behavior can be explained by the release of plasma after injection of saline solution. In the channeling application, the saline solution has no cooling effects as it potentially would in other Coblation procedures, when the saline solution is not only the source of the necessary ions, but also cools the surgical field by a continuous flow. It was surprising that the temperature during Coblation without a saline injection reached the maximum temperature of $380^{\circ} \mathrm{C}$ for only a short moment, which may be incidental. Without a saline injection, the Coblation wand seems to work like any other concentric bipolar electrode used with other systems and produces a spindle-like electrical field between the poles.

Figures 8 and 9 show averaged timelines for the application of $4 \mathrm{MHz}$ radiofrequency energy and the parallel bi- 


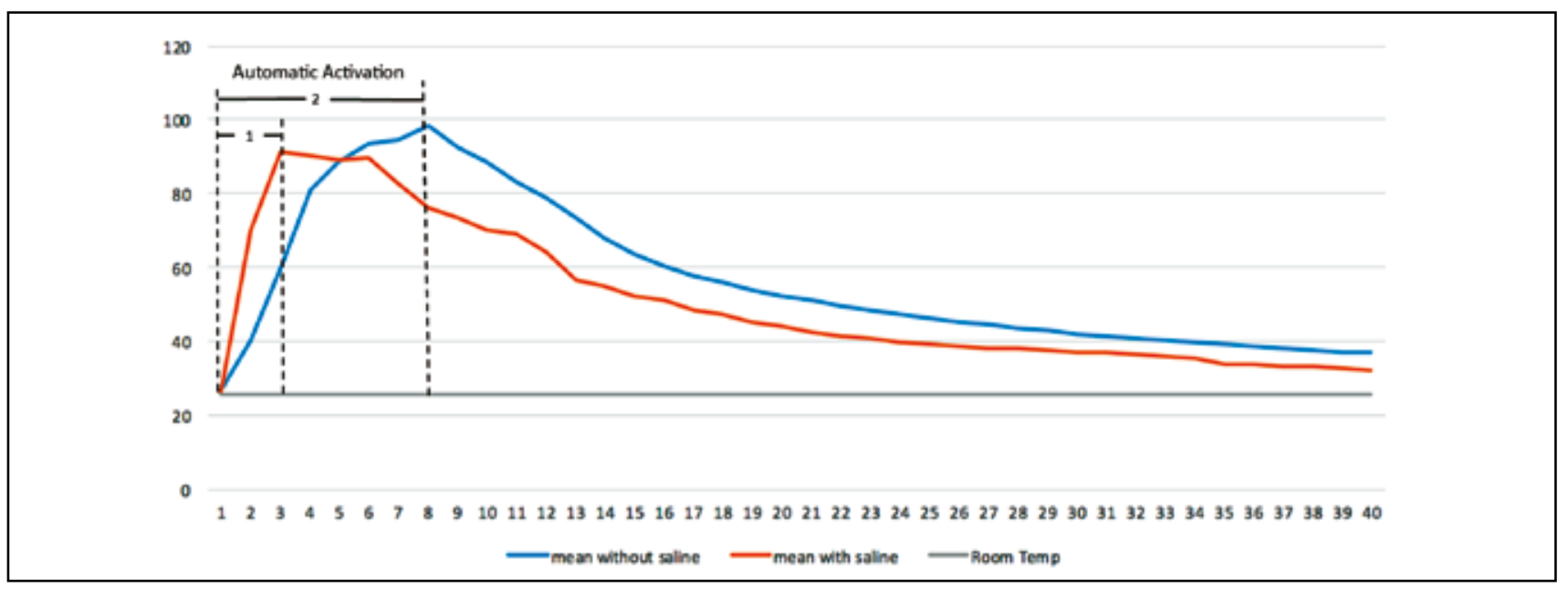

Figure 8 Mean temperature $\left({ }^{\circ} \mathrm{C}\right)$ during bipolar radiofrequency application, electrode length $10 \mathrm{~mm}$. Automatic energy limitation by tissue impedance measurement ("RaVoR" mode).

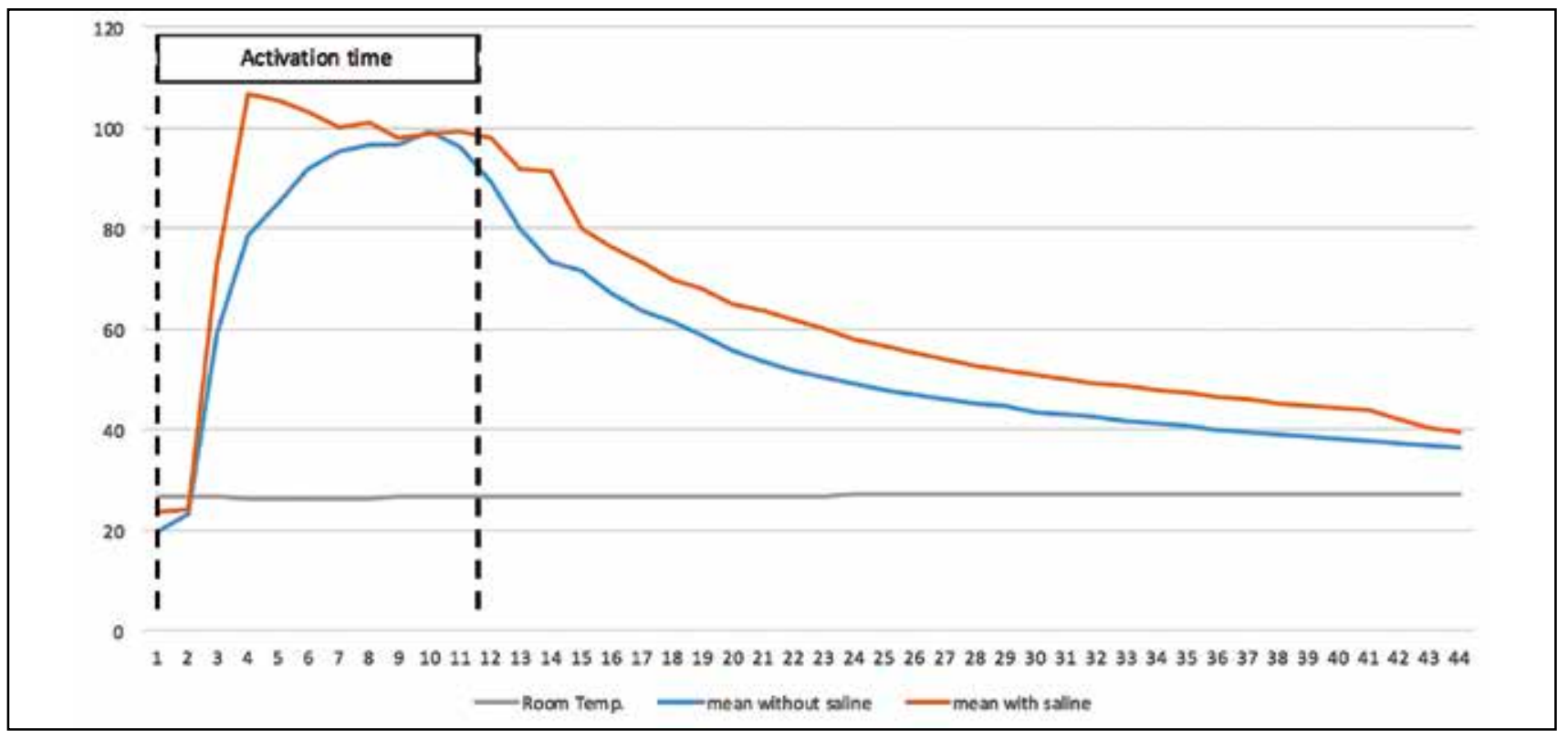

Figure 9 Mean temperature $\left({ }^{\circ} \mathrm{C}\right.$ ) during bipolar radiofrequency application, electrode length $25 \mathrm{~mm}$ by predetermined energy amount of $200 \mathrm{~J}$ ("Precise" mode).

polar needle electrodes operated in the RaVoR mode. The level of $100^{\circ} \mathrm{C}$ is reached for a few seconds only. There is no significant difference between the temperatures with and without saline injection. Figure 10 compares the mean temperatures $\left({ }^{\circ} \mathrm{C}\right)$ through all measurements.

B. Results of the histological investigations.

The results of temperature measurements correspond to the following typical histological results. The respiratory segment constitutes most of the volume of the nasal cavities. The turbinates mucosa consists of ciliated, pseudostratified columnar epithelium composed of five cell types. The lamina propria also contains mucous glands. The normal histology of tur-

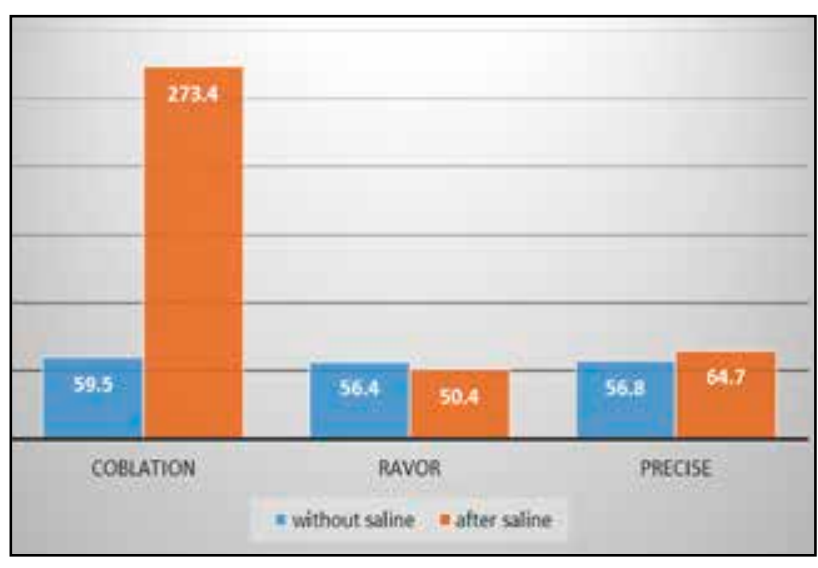

Figure 10 Comparison of mean temperatures $\left({ }^{\circ} \mathrm{C}\right)$ through all measurements. 


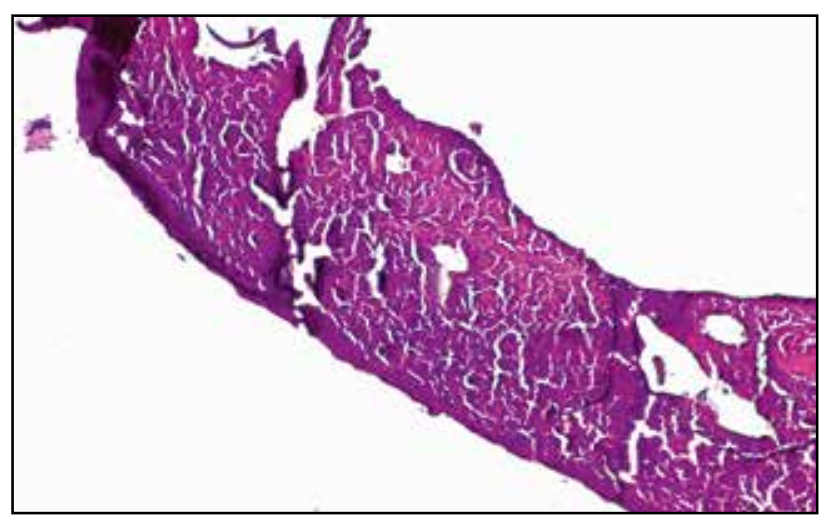

Figure 11 Turbinate mucosa, 40x, after Coblation, shows the structures of mucosa with accented coagulation of collagen and epithelia. Histological structures are no longer recognizable.

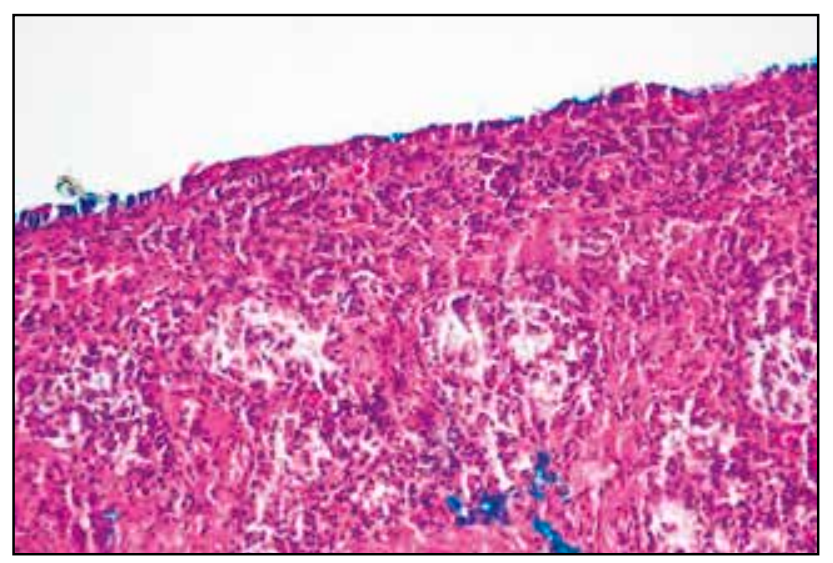

Figure 13 Turbinate mucosa after RF-application in RaVor mode (HE, 100 $\mathrm{x}$ ), surface. Development of steam in subepithelial areas with preserved gland structures and epithelium.

binates includes a dense network of large and irregularly shaped veins with thick muscular wall. The histological investigation after energy application showed tissue damage in all cases due to steam and temperature. However, differences between the effect of Coblation and Radiofrequency application are clearly visible. After Coblation, the type of the epithelium was not recognizable anymore (Figure 11). The lamina propria showed extensive collagen coagulation. After RF- application, the epithelia, as well as the mucinous glands in lamina propria, remained partly preserved (Figures $12-14$ ). Also, the vessels network was reduced. Heavy tissue damage was observed directly near the electrodes.

\section{DISCUSSIONS}

Energy-based treatment of the turbinates is the most common procedure for the treatment of chronic

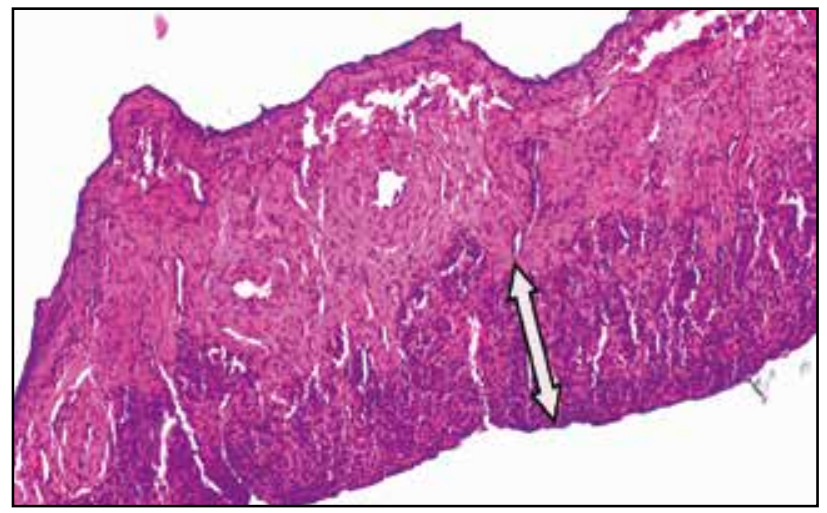

Figure 12 Turbinate mucosa after the application of radiofrequency current in RaVor mode. Mucosa and submucosa show coagulative changes in the subepithelial layer (yellow arrow). The deeper collagen layer and the epithelium are preserved ( $\mathrm{HE}, 40 \mathrm{x})$.

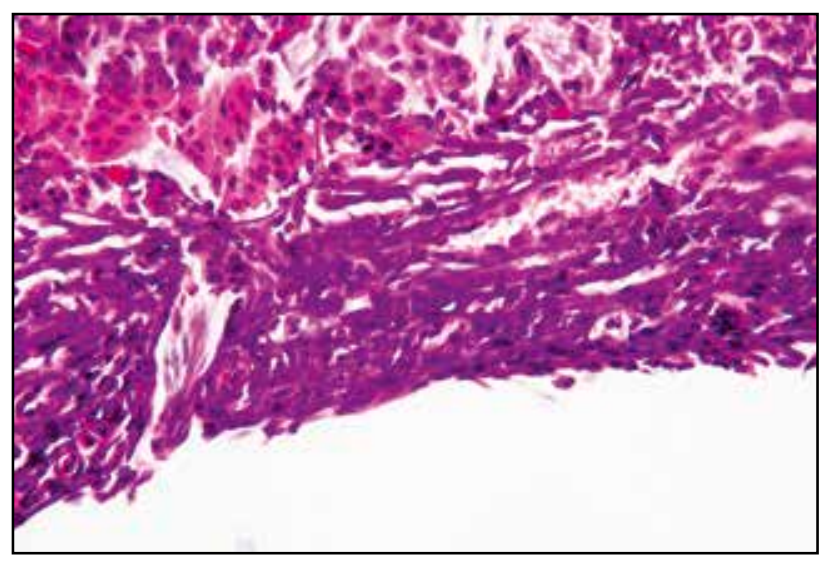

Figure 14 Turbinate mucosa after RF-application in RaVor mode (HE, 100 $\mathrm{x})$, lower side. The subepithelial layer (basal membrane) shows the condensation of cells with unidirectional nuclei as the typical effect of radiofrequency energy.

mucosal obstruction as measured by rhinomanometry $^{6}$. Different variations of "classic electrosurgery" as well as radiofrequency surgery are described, while the procedures mentioned here seem to be the most popular at present. The aim of this investigation was the visualization of potential differences, the verification of the manufacturer's claim of "cold ablation" (Coblation) and "gentle lesion creation" (Sutter) respectively and the optimization of these procedures.

It can be shown that by bipolar $4 \mathrm{MHz}$ radiofrequency surgery, a circumscribed submucosal lesion with coagulation and blockage of the vessels may be achieved, while the epithelial surface remains intact. Self-limitation by tissue impedance measurement produces a reproducible thermal effect. In a procedure following the manufacturer's recommendations, submucosal heat does not exceed $100^{\circ} \mathrm{C}$, and the average temperature generated is approximately $60^{\circ} \mathrm{C}$. We noticed that it seems to be of minor importance whether a short or long bipolar parallel needle is used. 
The double needles for RF applications used in this study have a diameter of $0.8 \mathrm{~mm}$ and generate an elliptic electrical field according to their length. Coblation wands have a diameter of nearly $2 \mathrm{~mm}$, which presumably cannot be decreased due to their specific design. The primary trauma from inserting the electrode is, therefore, remarkably bigger. According to the manufacturer's manual, the delivery of energy has to be repeated at given distances. The fact that the heat generated under the mucosal surface was in the same range as in the RF applications without injection of a conductive fluid was unexpected as Coblation current is delivered at a very low frequency of only 100.1 $\mathrm{kHZ}$. It is generally well known that the lateral heat effects are higher when the frequency of the current is lower ${ }^{9,10}$.

However, after injection of saline fluid, the temperature rapidly increases when using Coblation. Top temperatures of up to $1200^{\circ} \mathrm{C}$, average temperatures of $600^{\circ} \mathrm{C}$, and mean temperatures of $273^{\circ} \mathrm{C}$ are repeatedly reached. The ionized fluid releases the plasma as intended, but the cooling effect of a continuous flow as known from other Coblation applications, namely in orthopaedics in cartilage ablation, is missing. The submucous fluid cannot be exchanged, and Coblation is no longer a "low-temperature procedure". As it is visible in the histological patterns, the degree of tissue deterioration is much higher than after RF application.

The time of postoperative care is directly correlated with the damage of the mucosal surface, and, if the case, necrosis of the turbinal bone. It is difficult to find reliable data about the length of the postoperative phase. In an early report about turbinate Coblation, Bhattacharya ${ }^{5}$ reported crusting as well as postoperative bleeding without noting the incidence. Cavaliere ${ }^{10}$ found no difference in efficacy and complications between monopolar electrosurgical and Coblation turbinate reduction. Coblation is associated with more pronounced edema on day one after the intervention, which is attributed to the greater insult of the tissue by the device. This hypothesis would be in line with our experimental data on tissue temperatures. Shah ${ }^{11}$ reported favourable outcomes of Coblation turbinate reduction compared to bipolar electrosurgery intramural reduction. The study is affected by a small number of patients and authors who hypothesized that the bipolar system delivered heat up to $800^{\circ} \mathrm{C}$. It is obvious that these results cannot be transferred to $4 \mathrm{MHz}$ bipolar radiofrequency ablation as our data show consistently low temperatures for RF ablation.

Coblation is also very popular in tonsillectomy. Reports on postoperative results paint a mixed picture. In a Cochrane analysis by Burton ${ }^{12}$ on Coblation versus other techniques for tonsillectomy, only a small number of quality studies could be identified. The
Cochrane analysis discovered no evidence that Coblation resulted in lower post-op bleeding or less post-op pain compared with other methods. This is also in line with the findings of a very large cohort study performed in the UK, analyzing data from 11.796 tonsillectomies performed between 2003 and 2004. In this study, Lowe and van der Meulen ${ }^{13}$ reported complication rates for Coblation tonsillectomy to be higher than with most conventional techniques and technologies used for tonsillectomy. Favourable reports on Coblation tonsillectomy mostly cover the partial removal of the tonsils with some amount of tonsil tissue remaining ${ }^{14}$ or compared to methods with a high thermal footprint, such as monopolar blade electrode tonsil removal ${ }^{15}$.

For bipolar radiofrequency turbinate reduction, the reported results are mixed, too. Generally speaking, from a symptom-relief point of view, it must be considered as highly effective $\mathrm{e}^{7,16-19}$. We did not find reports of major complications in literature. However, minor complications or rather nuisances such as mild to moderate crusting one week after an intervention have been reported ${ }^{16}$, whereas others did not observe such phenomena $\left(\operatorname{Bran}^{7}\right)$. We speculate that with regards to the thermal impact, frequency of the applied current plays an important role, as most bipolar RF treatment devices for the lower turbinates operate at frequencies between $350 \mathrm{kHz}$ and $460 \mathrm{kHz}$. There is no systematic research into this subject for interstitial bipolar radiofrequency turbinate reduction. Earlier studies have shown the positive effect of frequency on the lateral thermal damage to tissue during cutting ${ }^{9,10,20}$. Cutting is a dynamic process as the electrode will glide through tissue, whereas interstitial tissue ablation is a stationary process.

Our study specifically looked at the differences in temperatures and histological outcomes between Coblation and $4 \mathrm{MHz}$ radiofrequency in the pig model, bearing in mind that the pig model certainly does not offer complete transferability to live human tissue. Keeping study conditions the same for both technologies, we argue that differences in results, if they occur in the model, will also be noted in live tissue. The pig model offers the advantage of an easy set-up, easy reproducibility and the absence of ethical concerns.

There is no doubt that Coblation is a useful and widely accepted methodology, but substantial doubts remain regarding "low-temperature-claims" in ENT applications. Our study shows that very high temperatures can indeed be achieved. Any presence of an electron-rich fluid such as saline solution, but potentially also blood, will lead to temperatures of $600^{\circ} \mathrm{C}$ and higher. During $4 \mathrm{MHz}$ bipolar radiofrequency ablation tissue, temperatures may very briefly and only slightly exceed $100^{\circ} \mathrm{C}$ and, as opposed to Coblation, may be lowered by the administration of electron-rich 
fluids such as saline solution or, potentially, blood.

The observed loss of epithelium is directly related to the length of the postoperative care, where reliable data cannot be found in the literature. The personal experience of one of the authors (KV) with 635 cases over 14 years using the technique above leads to the recommendation to see the patient 1 day after the operation for removing the sticky mucus, 1 week later for controlling the remaining mucosal reaction and after 1 month to measure the outcome by rhinomanometry ${ }^{3}$. Postoperative crusting with following sequestration of the turbinate bone was observed only in 2 cases at the very beginning of this series, when the energy was selected too high due to missing experience. This personal experience includes also children with allergic rhinitis at the beginning of desensitization.

In summary, our experiment has shown that for the reduction of turbinates due to chronic or recurrent congestion of the mucosa, application of radiofrequency at $4 \mathrm{MHz}$ is the less thermally burdensome procedure.

\section{CONCLUSIONS}

Thermometric measurements as well as histological analysis of porcine turbinate mucosa in $4 \mathrm{MHz}$ radiofrequency applications and Coblation have shown that RF applications only lead to minor thermal damage. The relevant literature suggests comparable clinical outcomes of the two technologies. Non-physiological release of plasma and heat in a closed system leads to non-controllable tissue deterioration. Furthermore, under commercial auspices, the authors recommend to use radiofrequency applications at proven settings rather than Coblation "channeling" for turbinate tissue reduction.

Acknowledgements: The authors wish to thank Dr. C. Hartig, Buchholz i.d. Nordheide/Germany and her co-workers for their cooperation in producing the histological specimens.

Funding statement: The study was supported by an educational grant of the University of Latvia.

Conflict of interest: Klaus Vogt is a consultant of Rhinolab GmbH Germany.

Contribution of authors: All authors have equally contributed to this work.

\section{REFERENCES}

1. Hol MK, Huizing EH. Treatment of inferior turbinate pathology: a review and critical evaluation of the different techniques. Rhinology. 2000;38(4):157-66.

2. Passali D, Loglisci M, Politi L, Passali GC, Kern E. Managing turbinate hypertrophy: coblation vs. radiofrequency treatment. Eur Arch Otorhinolaryngol.
2016;273(6):1449-53. DOI: 10.1007/s00405-015-3759-6. Epub 2015 Aug 31.

3. Vogt K, Enache R. Radiofrequency turbinotomy: basic, practice and statistics. Romanian Journal of Rhinology. 2012;2(7):133-8.

4. Cukurova I, Demirhan E, Cetinkaya EA, Yigitbasi OG. Long-term clinical results of radiofrequency tissue volume reduction for inferior turbinate hypertrophy. J Laryngol Otol. 2011;125(11):1148-51. DOI: 10.1017/ S0022215111001976. Epub 2011 Aug 26.

5. Bhattacharyya N, Kepnes LJ. Clinical effectiveness of coblation inferior turbinate reduction. Otolaryngol Head Neck Surg. 2003;129(4):365-71.

6. Shah AN, Brewster D, Mitzen K, Mullin D. Radiofrequency coblation versus intramural bipolar cautery for the treatment of inferior turbinate hypertrophy. Ann Otol Rhinol Laryngol. 2015;124(9):691-7. DOI: 10.1177/0003489415578709. Epub 2015 Mar 31.

7. Bran GM, Hünnebeck S, Herr RM, Hörmann K, Stuck BA. Bipolar radiofrequency volumetric tissue reduction of inferior turbinates: evaluation of short-term efficacy in a prospective, randomized, single-blinded, placebocontrolled crossover trial. Eur Arch Otorhinolaryngol. 2013;270 (2):595-601. DOI: 10.1007/s00405-012-2088-2. Epub 2012 Jun 28.

8. Woloszko J, Stalder KR, Brown IG. Plasma characteristics of repetitivelypulsed electrical discharges in saline solutions used for surgical procedures. IEEE Trans Plasma Sci. 2002;30(3):1376-83. DOI: 10.1109/TPS.2002.801612. Available from: https://ieeexplore.ieee.org/document/1158301/.

9. Maness W, Roeber FW, Clark RE, Cataldo E, Riis D, Haddad AW. Histologic evaluation of electrosurgery with varying frequency and waveform. J Prosthet Dent. 1978;40(3):304-8.

10. Mühlfay G, Horvath KU, Mocan SL, Budu VA, Ilyes IA, Doros CI, et al. A study on the type of lesions achieved by three electrosurgical methods and their way of healing. Rom J Morphol Embryol. 2015;56(4):1383-8.

11. Cavaliere M, Mottola G, Iemma M. Monopolar and bipolar radiofrequency thermal ablation of inferior turbinates: 20-month follow-up. Otolaryngol Head Neck Surg. 2007;137(2):256-63.

12. Burton MJ, Doree C. Coblation versus other surgical techniques for tonsillecstomy. Cochrane Databse Syst Rev. 2007;(3):CD004619.

13. Lowe D, van der Meulen J; National Prospective Tonsillectomy Audit. Tonsillectomy technique as a risk factor for postoperative haemorrhage. Lancet. 2004;364(9435):697-702.

14. Temple RH, Timms MS. Paediatric coblation tonsillectomy. Int J Pediatr Otorhinolaryngol. 2001;61(3):195-8.

15. Magdy EA, Elwany S, el-Daly AS, Abdel-Hadi M, Morshedy MA. Coblation tonsillectomy: a prospective, double-blind, randomised, clinical and histopathological comparison with dissection-ligation, monopolar electrocautery and laser tonsillectomies. J Laryngol Otol. 2008;122(3):282-90. Epub 2007 Nov 26.

16. Banhiran W, Assanasen P, Tantilipikorn P, Nujchanart N, Voraprayoon S, Bunnag C. Randomized study of temperature-controlled versus bipolar radiofrequency for inferior turbinate reduction. Eur Arch Otorhinolaryngol. 2015;272(10):2877-84. DOI: 10.1007/s00405-014-3410-y. Epub 2014 Nov 29.

17. Sahin-Yilmaz A, Oysu Ç, Devecioglu I, Demir K, Corey JP. Prediction of outcome of radiofrequency ablation of the inferior turbinates. Int Forum Allergy Rhinol. 2014;4(6):470-4. DOI: 10.1002/alr.21303. Epub 2014 Feb 14.

18. Demir U, Durgut O, Saradaydoglu G, Onart S, Ocakoglu G. efficacy of radiofrequency turbinate reduction: evaluation by computed tomography and acoustic rhinometry. J Otolaryngol Head Neck Surg. 2012;41(4):274-81.

19. Civelek S, Ozçelik M, Emre IE, Cakir BO, Turgut S. Comparison of radiofrequency applied to the total inferior choncha with application to its anterior third. Auris Nasus Larynx. 2010;37(5):589-93.

20. Hofmann TK, Schuler PJ, Bankfalvi A, Greve J, Heusgen L, Lang S, et al. Comparative analysis of resection tools suited for transoral robot-assisted surgery. Eur Arch Otorhinolaryngol. 2014;271(5):1207-13. DOI: 10.1007/ s00405-013-2615-9. 